\title{
SISTEMA DE GESTÃO PELA QUALIDADE: UMA PESQUISA NA SEARA DA GESTÃO PÚBLICA
}

\author{
Marcos dos Santos ${ }^{1}$, Luís Felipe Xavier Augusto de Oliveira ${ }^{2}$, Renato Santiago Quintal ${ }^{3}$, Rogerio dos Santos Lima ${ }^{4}$ \\ ${ }^{1}$ Doutorando em Engenharia do Produção. Universidade Federal Fluminense e Centro de Análises de Sistemas Navais. Rio de \\ Janeiro. Brasil. \\ 2 Mestrando em Engenharia do Produção. Universidade Federal Fluminense. Rio de Janeiro. Brasil
}
${ }^{3}$ Chefe de Departamento de Sistemas de Pagamento. Mestre em Contabilidade. Pagadoria de Pessoal da Marinha. Rio de Janeiro. Brasil
${ }^{4}$ Assessor de Gestão Estratégica e Presidente da Comissão de Responsabilidade Socioambiental. Centro de Análises de Sistemas Navais. Rio de Janeiro. Brasil

*E-mail para contato: rsantiago79@hotmail.com

\section{RESUMO}

No atual cenário onde existe demanda por parte da sociedade por serviços públicos de qualidade é possível perceber uma maior preocupação com sistemas de gestão da qualidade. As organizações contratantes de bens e serviços passam a estender seus requisitos de qualidade para suas contratadas, exigindo que essas passem a adotar sistemas de gestão da qualidade e de gestão ambiental e apresentem, no momento de sua contratação, certificações nesses sistemas de gestão. Nesse contexto, o presente artigo tem por objetivo investigar os fatores restritivos e os facilitadores afetos à certificação em gestão da qualidade em cinco organizações da Administração Pública. No que tange à seara metodológica, o presente artigo aplica a técnica do incidente crítico, proposta por Flanagan. Os instrumentos de coleta de dados utilizados foram as entrevistas não estruturadas com profissionais pertencentes ao quadro funcional das organizações pesquisadas. Adicionalmente, foi empreendido o levantamento de dados por meio de questionários - contendo perguntas fechadas e abertas - disponibilizados por e-mail. No que tange aos dados coletados a partir das entrevistas face a face e dos questionários, foi empreendida a análise multiparadigmal de Meyerson e Martin, a qual consiste em promover o relacionamento das percepções de determinado grupo com as perspectivas da Integração, Diferenciação e Fragmentação. Verificou-se que, nos dias atuais, as certificações assumem um papel relevante na seara empresarial, revelando-se como um diferencial competitivo no contexto globalizado, tanto para contratantes como contratadas. Contudo, questão crucial é observada quando as certificações deixam de ser uma atividade "meio" e passam a ser uma atividade "fim", implicando em significativo dispêndio de recursos materiais e humanos.

Palavras-chave: Gestão Pública; Gestão da Qualidade; Certificação de Processos.

\section{Introdução}

No atual cenário competitivo é possível perceber uma maior preocupação com sistemas de gestão da qualidade. Pombo e Magrini [1] destacam que, na economia globalizada, as organizações têm sido mais pressionadas a demonstrar um gerenciamento adequado em suas estruturas ambiental, social e econômica. A NBR ISO 9000 define como Gestão da Qualidade o "conjunto de atividades coordenadas para dirigir e controlar uma organização no que diz respeito à qualidade" [2]
Nesse contexto, as organizações contratantes de bens e serviços passam a estender seus requisitos de qualidade para suas contratadas, exigindo que essas passem a adotar sistemas de gestão da qualidade e de gestão ambiental e apresentem, no momento de sua contratação, certificações nos aludidos sistemas. De modo análogo, as organizações buscam a certificação no intuito de atestar a qualidade de seus produtos e processos, tornando-se mais competitivas. 
O presente artigo tem por objetivo investigar os fatores restritivos e facilitadores, existentes na gestão pública, afetos à certificação em gestão da qualidade em cinco organizações da Administração Pública. Para tanto, foi empregada a técnica do incidente crítico, proposta por Flanagan [3].

\section{Gestão de organizações públicas}

Para Santos et al [4], a década de 1990 foi marcada pelo início do processo de reforma na Administração Pública no Brasil, com o advento de mudanças verificadas em outros países na década anterior.

Uma onda de reformas no setor público iniciou-se na década de 1980 fundamentada na teoria do New Public Management [5]. Usualmente referido como a Nova Gestão Pública (NGP) ou Nova Administração Pública (NAP), esse movimento introduziu o conceito de Administração Pública com avaliação de desempenho e eficiência, a promoção da concorrência e de uma modalidade de gestão que destaca a liberdade gerencial, separando a burocracia pública das organizações. Como atributos fundamentais da NAP, identificam-se algumas variações que representam uma redução das distâncias entre o setor público e o privado [6].

Nessa mesma época, vários países já tinham iniciado um processo de diminuição do aparato estatal e de redução dos gastos públicos. Tal fato deveu-se ao esgotamento do modelo burocrático weberiano, contribuindo para que novos padrões gerenciais fossem introduzidos na Administração Pública, especialmente no Reino Unido e nos Estados Unidos e, posteriormente, em outros países na Europa e na América do Norte, como o Canadá [7].

No Brasil, a expressão "Nova Administração Pública" foi instituída e incorporada como Administração Pública Gerencial, tendo como seu principal propagador Luis Carlos Bresser Pereira, tanto como acadêmico, como Ministro de Estado, conduzindo os debates sobre a reforma do Estado, e sumarizando suas propostas e argumentos no Plano Diretor da Reforma do Aparelho de Estado (PDRAE) [8].

Falcão Martins [9] destaca que a crise da administração pública tem sido enfrentada por intermédio de uma substancial produção de tecnologia administrativa orientada à promoção de processos de transformação organizacional planejada no âmbito de organizações burocráticas públicas. Nessas circunstâncias, a temática afeta à viabilização de maior racionalidade para os sistemas estatais tem ocupado posição de destaque nas discussões acadêmica e política nos anos 1990.
A pesquisa de Batista [10] evidencia práticas de sucesso, contextualiza a Gestão do Conhecimento (GCO) nas organizações públicas na seara da Gestão Pública e sustenta o argumento de que o propósito da GCO em tais organizações deve ser vislumbrado de modo mais abrangente que em empresas do setor produtivo. Adicionalmente, destaca a relevância de se empreender uma política de gestão do conhecimento, com diretrizes e estratégias nitidamente formuladas, como forma de se viabilizar o processo de institucionalização da GCO na Administração Pública. Batista [10] destaca que é por meio da Gestão Organizacional que políticas públicas, programas e ações são realizados para satisfazer as demandas da sociedade. Nesse contexto, melhoria da gestão das organizações públicas é fundamental para o êxito da gestão governamental.

O estudo de Joia [11] mostra a variação de capital intelectual em organizações públicas envolvidas em empreendimentos government-to-government (G2G). Nesse sentido, o autor propõe o desenvolvimento de frame heurístico com a finalidade de avaliar o impacto de projetos G2G nos componentes do capital intelectual de agências públicas, ou seja, em seus capitais humano, organizacional, de relacionamento e de inovação. Aplicando-se esse frame heurístico a 30 empreendimentos G2G no Brasil, associando o Banco Central aos Tribunais de Justiça, a pesquisa em tela identificou um impacto positivo no capital intelectual das organizações envolvidas nesses empreendimentos. Igualmente, verificou-se que tais empreendimentos $\mathrm{G} 2 \mathrm{G}$ influenciaram os elementos constitutivos do capital intelectual de forma homogênea.

\section{Sistema de gestão da qualidade}

Para Juran e Gryna [12], qualidade consiste nos atributos do produto aderentes às necessidades dos clientes, proporcionando a sua satisfação em relação ao produto, bem como igualmente está associada à ausência de falhas.

Pinto e Soares [13] registram que a qualidade está inserida na base do sucesso no contexto empresarial, sendo um fator de competitividade e de diferenciação entre organizações. De fato, o desenvolvimento de uma cultura baseada na qualidade abre caminho à eficácia e à eficiência organizacional, possibilitando um maior lucro com menor custo.

A International Organization for Standardization (ISO) é uma organização não governamental criada para promover o desenvolvimento das atividades de normalização, funcionando como um elo entre os setores público e privado. É composta por 162 países e a sua sede situa-se em Genebra, na Suíça [14].

A Norma ISO 9001 tem como finalidade especificar requisitos voltados para um sistema de gestão da qualidade apto a 
ser empregado no âmbito interno das organizações, para certificação ou para fins contratuais. Convém destacar que a norma em tela encontra-se focada na eficácia do sistema de gestão da qualidade, objetivando aderir aos requisitos do cliente [15].

Em alguns fóruns, a certificação ISO 9001 ainda é entendida como burocracia. Para outros, representa uma oportunidade de introduzir reformas para inserir as instituições no caminho da modernização administrativa, perseguindo-se maior eficácia e eficiência. A prática tem evidenciado distintas vantagens nos mais variados setores. Nesse contexto, o propósito da ISO 9001:2015 é proporcionar vantagem competitiva por meio da qualidade. Trata-se de um padrão internacional para a implementação de um sistema de gestão da qualidade calcado em oito princípios destinados a melhorar o desempenho organizacional, a saber: (1) enfoque no cliente; (2) liderança; (3) envolvimento das pessoas; (4) abordagem a processos; (5) abordagem sistêmica à gestão; (6) melhoria contínua; (7) abordagem efetiva à tomada de decisão; e (8) relação com os fornecedores mutuamente benéfica. A Figura 1 abaixo apresenta de forma esquemática a melhoria contínua viabilizada pelo sistema de gestão da qualidade.

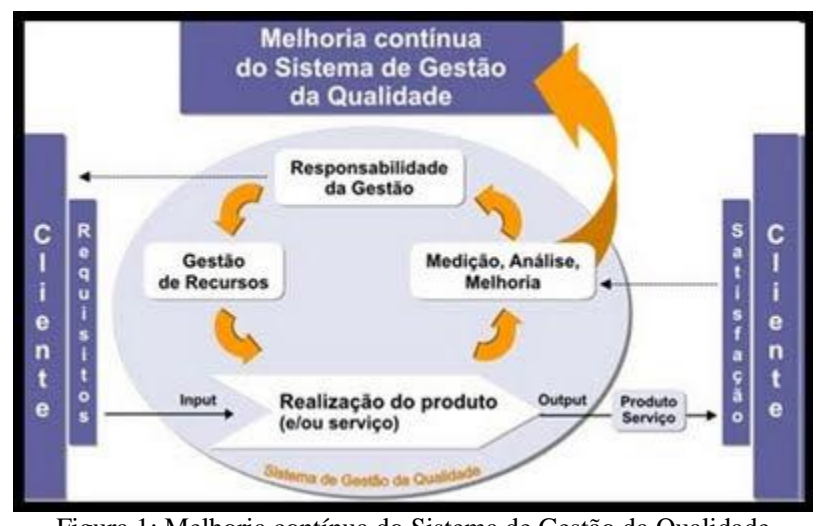

Figura 1: Melhoria contínua do Sistema de Gestão da Qualidade Fonte: ASSOCIAÇÃO BRASILEIRA DE NORMAS TÉCNICAS [15].

\section{Certificação}

De acordo com Ganhão e Pereira [16], certificar a conformidade de um produto ou serviço corresponde à ação de comprovar que o aludido produto ou serviço encontra-se em conformidade normas ou especificações estipuladas, transmitindo confiança ao cliente. Adicionalmente, Madeira et al. [17] afirmam que a certificação assegura, minimamente, que há alta probabilidade de que os processos sejam executados de um modo sistematizado, documentado e bem respaldado, propiciando, por esse motivo, confiança.
Coelho [18] observa que a obtenção da certificação ISO 9001 revela o resultado do empenho de uma organização que, ao longo de um processo de melhoria contínua, pretende planejar, executar, verificar e agir, à luz do ciclo PDCA, esses mesmos processos a fim de lograr fazer sempre melhor, com menor custo e no menor tempo possível.

Para Casadesús et al. [19], qualquer empresa que cogite implementar ou certificar o seu sistema de gestão de qualidade tem razões que a levaram a tomar tal decisão. As motivações para a certificação podem ser de ordem interna ou externa. Não se pode dizer, contudo, que as motivações das organizações para a certificação pela ISO 9001 sejam unicamente internas ou externas, quando, na verdade, são simultâneas, apesar de existir sempre uma que é mais relevante na determinação da motivação para a obtenção da certificação.

\section{Incidente crítico}

Segundo Flanagan, a técnica do incidente crítico baseia-se em:

[...] um conjunto de procedimentos para a coleta de observações diretas do comportamento humano, de modo a facilitar sua utilização potencial na solução de problemas práticos e no desenvolvimento de amplos princípios psicológicos, delineando também procedimentos para a coleta de incidentes observados que apresentem significação especial e para o encontro de critérios sistematicamente definidos [3]

Para Nogueira et al. [20], a técnica em comento abrange a análise de incidentes relatados por pessoas aptas para julgamento acerca da eficiência de determinado trabalho, a partir do exame destes incidentes, bem como a compilação dos comportamentos eficientes ou não para o propósito do trabalho.

Para a aplicação da técnica, Flanagan [3] define cinco passos fundamentais a serem seguidos, relacionados aos seguintes tópicos: objetivos gerais; planos e especificações; coleta de dados; análise dos dados; interpretações e relatório.

No que concerne aos objetivos gerais, observa-se que a formulação do objetivo geral de uma atividade é condição sine qua non para a avaliação de comportamentos específicos. Sem o entendimento do objetivo da atividade, não há como se mensurar adequadamente a eficácia no desenvolvimento da mesma. O objetivo geral deve ser uma declaração sucinta, obtida das autoridades do campo, que expresse em termos simples aqueles objetivos com os quais a maioria das pessoas anuiria [3].

No âmbito de planos e especificações, é essencial para o sucesso da aplicação da técnica que um conjunto de instruções claras e específicas seja sistematizado e multiplicado entre os observadores. É necessário delimitar a situação a ser considerada (lugar, pessoas, condições e atividades), decidir o grau de 
relevância do comportamento em relação ao objetivo geral da atividade, pormenorizar uma escala de intensidade do efeito (positivo e negativo) sobre o objetivo geral da atividade, e estabelecer os critérios de seleção e treinamento dos observadores [3].

A coleta de dados é fortemente impactada pela atualidade dos fatos. Quanto mais recentes forem os fatos nas mentes dos observadores, mais esmiuçadas serão as informações coletadas. A coleta de dados tem sido mais viabilizada por meio de quatro procedimentos: entrevistas individuais, grupos focais, envio de questionários por correio ou internet, e formas de registro no momento em que ocorre o incidente (formulários ou relatórios). A adequada confecção das perguntas é crucial para o sucesso da coleta. Elas devem ser breves, claras e relacionadas ao objetivo geral da atividade [3].

A análise dos dados tem como propósito sumarizar e descrever os dados de forma eficiente, incrementando, dessa forma, a utilidade (compreensão, especificidade e validade) dos dados coletados e já descritos. Devem-se definir os critérios referenciais que viabilizem a construção de categorias de incidentes aderentes à finalidade da pesquisa. $\mathrm{O}$ passo posterior à escolha das categorias é a definição do grau de especificidadegeneralidade a ser aplicado na determinação dos comportamentos gerais que estarão introduzidos na categoria. Como esta fase tende a ser mais subjetiva, recomenda-se que a triagem das categorias e a deliberação acerca dos comportamentos gerais sejam feitas por observadores especialistas externos [3].

Por ocasião da etapa de interpretações e relatório, tanto as restrições da pesquisa como o valor de seus resultados necessitam ser destacados [3].

\section{Aspectos metodológicos}

Para Gil [21], o delineamento da pesquisa pode ser interpretado como o planejamento empreendido de forma ampla e expressa, pois contempla os fundamentos metodológicos, a definição dos objetivos, o ambiente da pesquisa e, por fim, a determinação das técnicas de coletas e análise de dados. No que tange à seara metodológica, o presente artigo aplica a técnica do incidente crítico, proposta por Flanagan [3]. Para tal, foram delimitados os objetivos, os planos e as especificações a serem observados.

Os instrumentos de coleta de dados utilizados foram as entrevistas não estruturadas com profissionais pertencentes ao quadro funcional das organizações pesquisadas, ligadas aos setores: contratação de bens e serviços; gestão da qualidade; saúde; meio ambiente e segurança; e normatização e certificação. Adicionalmente, foi empreendido o levantamento de dados por meio de questionários - contendo perguntas fechadas e abertas - disponibilizados por e-mail. Das 60 correspondências eletrônicas enviadas, 24 foram respondidas, conforme Quadro 1 lançado abaixo.

Quadro 1:Cargos dos respondentes dos questionários disponibilizados por email

\begin{tabular}{|c|c|}
\hline Instituição & $\begin{array}{l}\text { Cargos dos respondentes dos questionários } \\
\text { disponibilizados por e-mail }\end{array}$ \\
\hline $\begin{array}{l}\text { Instituição } \\
\text { pública de } \\
\text { pesquisa } \\
\text { situada em } \\
\text { Brasília. }\end{array}$ & $\begin{array}{l}\text { Assessor do Núcleo de Inovação Tecnológica, } \\
\text { Encarregado da Divisão de Prospecção Tecnológica, } \\
\text { Assessor para os Fundos Setoriais junto ao Ministério } \\
\text { da Defesa e ao Ministério da Ciência, Tecnologia e } \\
\text { Inovação; Assessor de Projetos Especiais; } \\
\text { Encarregado da Divisão de Planejamento. }\end{array}$ \\
\hline $\begin{array}{lr}\text { Instituição } & \\
\text { pública } & \text { de } \\
\text { pesquisa } & \\
\text { situada } & \text { na } \\
\text { Região dos } \\
\text { Lagos. }\end{array}$ & $\begin{array}{l}\text { Chefe do Departamento de Pesquisas; Encarregado do } \\
\text { Núcleo de Coordenação e Apoio do Departamento de } \\
\text { Pesquisa; Gerente de Meio Ambiente; Gerente de } \\
\text { Relações Institucionais; Assessoria de Comunicação } \\
\text { Social; Assessor de Gestão Estratégica; Encarregado } \\
\text { do Grupo de Finanças; Assessor Jurídico. }\end{array}$ \\
\hline $\begin{array}{ll}\text { Instituição } & \\
\text { pública } & \text { de } \\
\text { pesquisa } & \\
\text { situada } & \text { no } \\
\text { Vale } & \text { do } \\
\text { Paraíba } & \\
\text { Paulista. } & \end{array}$ & $\begin{array}{l}\text { Gerente de Planejamento; Assessor Jurídico; Gerente } \\
\text { de Propriedade Intelectual; Gerente de Transferência } \\
\text { de Tecnologia; Gerente de Prospecção Tecnológica; } \\
\text { Gerente de Relacionamento Externo. }\end{array}$ \\
\hline $\begin{array}{l}\text { Instituição } \\
\text { pública de } \\
\text { pesquisa } \\
\text { situada em } \\
\text { Brasília. } \\
\end{array}$ & 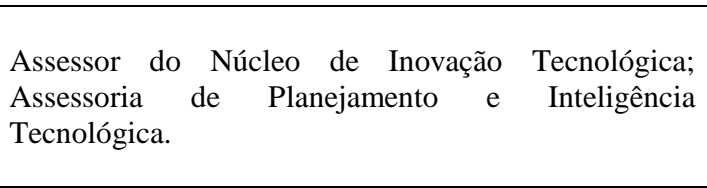 \\
\hline $\begin{array}{l}\text { Instituição } \\
\text { pública } \\
\text { pesquisa } \\
\text { situada } \\
\text { noroeste } \\
\text { paulista. }\end{array}$ & $\begin{array}{l}\text { Assessor de Planejamento Corporativo; Gerente do } \\
\text { Conhecimento; Gerente Financeira. }\end{array}$ \\
\hline
\end{tabular}

Fonte: Elaborado pelos autores a partir de dados da pesquisa

No que tange aos dados coletados a partir das entrevistas face a face e dos questionários, foi empreendida a análise multiparadigmal de Meyerson e Martin [22], a qual consiste em promover o relacionamento das percepções de determinado grupo com as perspectivas da Integração, Diferenciação e Fragmentação. A perspectiva da Integração evidencia a existência de percepções comuns aos entrevistados e aos respondentes dos questionários, no que tange aos diferentes aspectos abordados. A Diferenciação aponta para a presença de consenso apenas dentro dos grupos que compõem a organização e, por fim, a Fragmentação revela a ausência de conformidade dos integrantes da organização [23]. Por fim, procedeu-se à análise e à codificação dos dados a fim de viabilizar a elaboração do relatório de pesquisa. 


\section{Análise dos resultados e discussão}

A partir das entrevistas realizadas, os incidentes observados e coletados foram agrupados e categorizados de acordo com a sua relevância. Primeiramente, os eventos foram divididos em três categorias: benefícios, dificuldades e riscos.

Para cada uma dessas categorias, surgiram duas subcategorias, a saber: a categoria "benefícios" foi subdividida em nas subcategorias "qualidade em todo processo" e "maior chance de obter contratos"; "dificuldades" foi subdividida em "patrocínio da alta administração" e "custo de implementação e manutenção"; por fim, "riscos" subdividiu-se em "atender os requisitos apenas para a certificação" e "tornar os processos burocráticos", conforme pode ser observado na Figura 2.

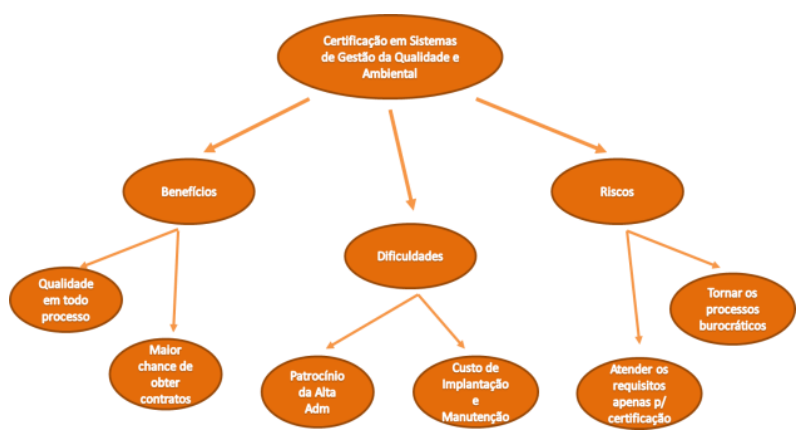

Figura 2: Categorias e subcategorias dos incidentes observados e coletados Fonte: elaborado pelos autores

Compreende-se por "benefícios" as vantagens associadas à implementação de um sistema de gestão da qualidade e ambiental, bem como a sua certificação. Nesse contexto, os principais temas abordados pelos entrevistados dizem respeito ao fato de que a implementação de um sistema de gestão eleva a chance de que haja qualidade em todo o processo produtivo, ou seja, desde a seleção de fornecedores, passando pela compra dos insumos, qualidade no processo de produção, de gestão de recursos até o produto final.

Outra temática que apresentou grande relevância nas entrevistas está associada à elevação das chances de se auferir novos contratos, a partir da adoção de boas práticas de gestão, comprovadas por certificação.

As principais dificuldades apontadas, tanto no processo de certificação como no de contratação de empresas certificadas, estão associadas ao "patrocínio da alta administração", quando os respondentes entendem que, quando não há o apoio da direção da organização, o processo se torna moroso e perde prioridade. Adicionalmente, foi tratada a questão dos custos de implementação e de manutenção do sistema de gestão de qualidade.
No que tange à categoria "riscos", observa-se que as pessoas passam a cumprir somente os requisitos mínimos necessários à certificação, sem atuar de forma proativa em prol da qualidade; trata-se de temática afeta à subcategoria "atender aos requisitos apenas por conta da certificação". Outra subcategoria que merece destaque é "tornar os processos burocráticos", uma vez que passa a ser demandada uma maior quantidade de documentos, procedimentos e auditorias.

\section{Conclusões e sugestões de novas pesquisas}

O presente artigo teve por objetivo investigar os fatores restritivos e facilitadores, existentes na gestão publica afetos à certificação em gestão da qualidade em cinco organizações da Administração Pública. Para tanto, foi empregada a técnica do incidente crítico, proposta por Flanagan [3]

Verificou-se que, nos dias atuais, as certificações assumem um papel relevante na seara empresarial, revelando-se como um diferencial competitivo no contexto globalizado, tanto para contratantes como contratadas. Para as empresas contratantes, corresponde a uma garantia de que os fornecedores obedecem a processos rígidos e bem definidos.

Contudo, questão crucial é observada quando as certificações deixam de ser uma atividade "meio" e passam a ser uma atividade "fim", implicando em significativo dispêndio de recursos materiais e humanos. Dessa forma, deixa de ser um diferencial competitivo e passa a ser um peso carregado por todos os setores da empresa, comprometendo o foco da organização nas suas competências essenciais.

Nesse contexto, cabe à alta administração da empresa a implantação e manutenção dos sistemas de gestão e suas respectivas certificações, bem como encontrar o ponto de equilíbrio e o bom dimensionamento desses sistemas a fim de que eles se mantenham como um diferencial competitivo e não asfixiem os demais setores da organização.

Em termos de limitação da pesquisa, cabe destacar que o resultado da pesquisa está adstrito ao presente estudo, sendo impossível a sua generalização irrestrita a outras organizações.

Em última análise, a título de sugestão para pesquisas futuras, recomenda-se empreender estudo aplicado a um caso concreto na seara da Administração Pública Direta ou Indireta, empregando-se questionários e entrevistas estruturadas e/ou não estruturadas, com o propósito de identificar oportunidades de melhoria na gestão pública a partir da adoção de modelos de gestão que contemplem parcerias com o terceiro setor, como forma de mitigar as ineficiências de cada parceiro e aproveitar as suas potencialidades. 


\section{SYSTEM OF QUALITY MANAGEMENT: A SEARCH ON HARVEST OF PUBLIC MANAGEMENT}

ABSTRACT: In the current scenario where there is demand from society for quality public services can realize a greater concern with quality management systems. Contracting organizations goods and services will extend their quality requirements for their contractors, demanding that these start to adopt quality management systems and environmental management and present, at the time of hiring, certifications these management systems. In this context, this paper aims to investigate the restrictive factors and affections facilitators to quality management certification in five organizations of Public Administration. Regarding the methodological harvest, this article applies the technique of critical incident, proposed by Flanagan. The data collection instruments used were the unstructured interviews with professionals from the workforce of the surveyed organizations. In addition, data collection through questionnaires was undertaken - with closed and open questions available by email. With respect to data collected from the face to face interviews and questionnaires, was undertaken to multiparadigmal analysis Meyerson and Martin, which is to promote the relationship of perceptions of a particular group with the prospects of integration, differentiation and fragmentation. It was found that, nowadays, certifications play an important role in business harvest, revealing itself as a competitive advantage in the global context, both for contractors and contractors. However, crucial issue is observed when the certificates are no longer an activity "through" and become an activity "end", resulting in significant waste of material and human resources.

Keywords: Public Administration; Quality management; Process certification.

\section{Agradecimento}

Os autores agradecem aos ilustres pareceristas da Revista Tecno-Lógica pelas críticas e sugestões feitas à versão original do texto.

\section{Referências}

[1] POMBO, F. R.; MAGRINI, A. Panorama de aplicação da norma ISO 14001 no Brasil. Revista Produção, v. 15, n. 1, p. 1-10, 2008.

[2] ASSOCIAÇÃO BRASILEIRA DE NORMAS TÉCNICAS. Sistemas de gestão da qualidade - fundamentos e vocabulário. ABNT NBR ISO 9000, 2000.

[3] Flanagan, J. C. A técnica do incidente crítico. Arq. Bras. de Psicologia Aplicada, v.21, n.2, 1973.
[4] SANTOS, M. F. B. et al. A sistemática de Organizações Militares Prestadoras de Serviço (OMPS): perspectivas e tendências em 19 Anos de existência. Rios Eletrônica (FASETE), v. 7, p. 141-153, 2013.

[5] 5) POllit, C.; BOUCKaERT, G.: Public Management Reform: A Comparative Analysis. Oxford University Press. Dezembro, 1999.

[6] BEVIR, M.; RHODES, R.; WELLER, P.. Traditions of governance: interpreting the changing role of the public sector. Public Administration, v. 81, $\mathrm{n}^{\circ} 1,2003$.

[7] HOOD, Christopher. A public management for all seasons? Public Administration. v. 69, p. 3-19, 1991.

[8] COSTA, F. L. da: Brasil: 200 anos de Estado; 200 anos de administração pública; 200 anos de reformas. Revista de Administração Pública. v. 42, n. 5. Rio de Janeiro, p.829-74, set/out, 2008.

[9] FALCÃO MARTINS, H. Uma Análise dos Paradigmas de Adminstração Pública à Luz do Contexto do Estado Social. Parcerias Estratégicas, p. 140-169, 1996.

[10] BATISTA, F. F. Governo que aprende: gestão do conhecimento em organizações do executivo federal. Texto para Discussão n. 1022. Brasília: Ipea, jun. 2004.

[11] JOIA, L. A. Governo eletrônico e capital intelectual nas organizações públicas. RAP, Rio de Janeiro, n.43, p. 1379-1405, nov./dez. 2009.

[12] JURAN, J. M.; GRYNA, F. M. Juran controle da qualidade handbook: conceitos, políticas e filosofia da qualidade. Volume I. 4 a Edição São Paulo: Makron Books do Brasil/McGraw Hill, 1991.

[13] PINTO, A.; SOARES, I. Sistemas de Gestão da Qualidade - Guia para a sua Implementação. Lisboa, Edições Sílabo, 2010.

[14] INTERNATIONAL ORGANIZATION FOR STANDARDIZATION. About ISO, Introduction. Disponível em: <http://www.iso.org/iso/en/aboutiso/introduction/index.html>. Acesso em: 1 jun. 2015 .

[15] ASSOCIAÇÃO BRASILEIRA DE NORMAS TÉCNICAS. Sistemas de gestão de qualidade-requisitos. ABNT NBR ISO 9001, 2015.

[16] GANHÃO, F. N.; PEREIRA, A.. A Gestão da Qualidade: como implementá-la na empresa. Lisboa, Editorial Presença, 1992.

[17] MADEIRA, A. et al. Manual Prático para a Gestão e Qualidade nas Organizações. Lisboa, Edições Verlag Dashöfer, 2009.

[18] COELHO, M. Certificação: Inovar para Ganhar o Futuro. Dossiê especial Qualidade do Jornal Expresso, 2006.

[19] CASADESÚS, M.; GERUSA, De HERAS, I. Benefits of ISO 9000 Implementation in Spanish industry. European Business Review, Vol. 13, $n^{\circ}$. 6, 327-335, 2001.

[20] NOGUEIRA, M.S.; MENDES,I.A.C.; TREVIZAN, M.A.; HAYSHIDA, M. Técnica dos incidentes críticos: uma alternativa metodológica para análise do trabalho em áreas cirúrgicas. Rev. Paul. Enf., v.12, n.3, set./dez. 1993.

[21] GIL, A.C. Como elaborar projetos de pesquisa. 5. Ed. São Paulo: Atlas, 2010. 
[22] MEYERSON, D.; MARTIN, J. Cultural change: an integration of three different views. Journal of Management Studies, v. 24, n. 4, p. 623-647, 1987.

[23] CARRIERI, A. P. Uma opção teórico-metodológica para pesquisas sobre culturas nas organizações. In: CARRIERI, A. P.; CAVEDON, N. R.; SILVA, A. R. L. Cultura nas organizações: uma abordagem contemporânea. Curitiba: Juruá, 2008. p. 19-33.

\section{Apêndice A}

\section{Questionário}

Este questionário faz parte de um trabalho acadêmico sobre os fatores restritivos e facilitadores, existentes na gestão publica afetos à certificação em gestão da qualidade. Gostaríamos de solicitar sua contribuição para esta pesquisa, respondendo as perguntas deste questionário. Lembramos que a identificação do respondente será preservada e que as informações coletadas neste estudo não serão tratadas individualmente, somente os resultados gerais serão divulgados.

1. Em qual Organização você trabalha? Que cargo ocupa?

2. Há quanto tempo ocupa o atual cargo nessa Organização?

( ) Menos de um ano

( ) Entre um e três anos

( ) Entre três e cinco anos

( ) Mais de cinco anos

3. A Organização em que você trabalha dispõe de um Sistema de Gestão da Qualidade?

( ) Sim. (Por favor, continue a responder o questionário)

( ) Não. (Obrigado. O questionário está encerrado)

4. O Sistema de Gestão possui certificação ISO 9001 ?

( ) Sim. (Por favor, continue a responder o questionário)

( ) Não. (Obrigado. O questionário está encerrado)

5. Por que implementar Sistemas de Gestão da Qualidade?

6. Quais são os principais obstáculos à implementação?

7. Existe participação dos níveis hierárquicos mais elevados na implementação de Sistemas de Gestão da Qualidade? Se sim, de que forma essa participação pode ser verificada?

8. Qual o papel dos usuários na manutenção e implementação de Sistemas de Gestão da Qualidade?

9. Qual a importância em obter certificações em Sistema de Gestão da Qualidade?
10. Ao contratar empresas fornecedoras de bens ou prestadora de serviços, por que incluir certificações de Sistemas de Gestão da Qualidade como exigência contratual?

11. Fornecedores ou prestadores de serviços certificados são garantia de que os produtos ou serviços contatados terão a qualidade esperada?

12. É possível notar algum tipo de incremento nos custos por conta da exigência de certificados em Sistemas de Gestão da Qualidade?

13. É possível identificar se a exigência de certificados em Sistemas de Gestão da Qualidade representa aumento na dificuldade em licitar bens ou serviços?

O questionário está encerrado. Muito obrigado pela sua participação e pelo seu tempo! 